\title{
Psychosocial support services provided for Syrian refugees with disabilities: a systematic review and thematic analysis
}

\author{
Ali M. Alodat ${ }^{1 *} \mathbb{D}$, Hanan I. Alshagran ${ }^{1}$ and Al-Muatasem M. Al-Bakkar²
}

\begin{abstract}
This study systematically reviewed and thematically analyzed studies that investigated psychosocial support services provided to Syrian refugees with disabilities between 2011 and 2020. Nine studies published in the English language were identified from database searches (Google Scholar, PsychInfo, EBSCOhost, Web of Science, and Scopus). Results showed that the forms of psychosocial support services provided to Syrian refugees with disabilities were varied based on the nature of the study and the disability type. The results also provided detailed information about methods, participants, and findings of the identified studies. The thematic analysis results identified six themes that represent the factors related to the psychosocial support services, which were assessment, mental health, psychological well-being, rehabilitation, social participation, and vulnerability. This study provided a set of recommendations that may improve the quality of mental health and psychosocial support services provided to Syrian refugees with disabilities and their families, which are professional development, researches, and policy reforming.
\end{abstract}

Keywords: Syrian refugees, Refugees with disabilities, Psychosocial support, Systematic review, Thematic analysis

\section{Introduction}

\section{Background}

The number of refugees and asylum seekers has rapidly increased in recent decades, which has become a significant global challenge $[1,2]$. The most critical challenges facing hosting countries were providing refugees with protection and essential services, such as shelter, food, health care, and education [3-5]. Refugees are at risk of post-traumatic stress syndrome (PTSD) and other mental and psychological disorders that may affect their functional and social skills [6-8]. These mental and psychological disorders are results of a range of events and factors that refugees who fled from war have experienced, such as the death of a loved person, separation from family, or being subject to or witnessing violent

\footnotetext{
* Correspondence: Ali.alodat@yu.edu.jo

${ }^{1}$ Counseling and Educational Psychology Department, Yarmouk University, Irbid, Jordan

Full list of author information is available at the end of the article
}

acts $[8,9]$. However, mental health and psychosocial support services (MHPSS) are considered as an essential health service based on the fact that refugees are at risk of mental disorders that may affect their functional and social skills [6-8]. There are a considerable number of studies that investigated mental health and social support services provided for refugees; however, it is important to explore to what extent these studies extensively investigated psychosocial services provided to refugees with disabilities in disaster contexts [10]. Refugees with disabilities are the most vulnerable and invisible group of refugees and asylum seekers, who need humanitarian services like psychosocial support services (PSS) [11-16]. Hence, it is crucial to shed light on scientific researches that focused on providing mental health services to a profoundly affected population, such as refugees with disabilities.

\section{Springer Open}

(- The Author(s). 2021 Open Access This article is licensed under a Creative Commons Attribution 4.0 International License, which permits use, sharing, adaptation, distribution and reproduction in any medium or format, as long as you give appropriate credit to the original author(s) and the source, provide a link to the Creative Commons licence, and indicate if changes were made. The images or other third party material in this article are included in the article's Creative Commons licence, unless indicated otherwise in a credit line to the material. If material is not included in the article's Creative Commons licence and your intended use is not permitted by statutory regulation or exceeds the permitted use, you will need to obtain permission directly from the copyright holder. To view a copy of this licence, visit http://creativecommons.org/licenses/by/4.0/. 


\section{Syrian refugees with disabilities}

The Syrian conflict started in March 2011 after a military attack against protesters; then, the situation in Syria had evolved into a civil war [17-19]. The Syrian crisis was the worst humanitarian crisis in modern history, which resulted in more than six million refugees in Turkey, Lebanon, Jordan, Iraq, Egypt, and other European countries as well as seven million internally displaced people (IDPs) [20-22]. In general, wars and disaster situations are associated with an increasing ratio of refugees and IDPs with disabilities. In 2016, the World Health Organization (WHO) estimates that the number of refugees and IDPs with severe and moderate disabilities worldwide was more than ten million people [12]. For the Syrian situation specifically, the HelpAge International report in 2014 estimated that $30 \%$ of Syrian refugees have special needs $[11,13]$.

According to the WHO, disability is an umbrella term that refers to impairment conditions that impose environmental and social barriers to individuals' activities [23]. The Diagnostic and statistical manual of mental disorders (DSM-5) divided the disability concept into primary groups that included intellectual disabilities, communication disorders, autism spectrum disorder, attention-deficit-hyperactivity disorder, specific learning disorder, motor disorders, and other neurodevelopmental disorders [24]. The Individuals with Disabilities Education Act, IDEA (2004) defined the disability categories to include intellectual disability, hearing impairment, language impairment, visual impairment, emotional disorders, orthopedic impairment, ASD, health impairment, specific learning disability, and multiple disabilities.

The Syrian crisis delivered a large group of in need refugees, yet refugees with disabilities are the most affected and vulnerable group of Syrian refugees [13, 15, 25-27]. Statistics of 2014 showed that $22 \%$ of Syrian refugees in Jordan and Lebanon had disabilities [15] while other statistics specified that this ratio might be much more than that especially since $65 \%$ of the elderly Syrian refugees suffer from physical or psychological disabilities [13]. These statistics indicated that $13.4 \%$ of registered refugees with disabilities have intellectual disabilities, $44.2 \%$ physical disabilities, $42.5 \%$ sensory disabilities, and $20 \%$ multiple disabilities. Moreover, the disability prevalence in Nizip 2 camp in Turkey was $1.29 \%$ [15, 25]. Statistics also indicate that the global prevalence of disability is about $15 \%$ of the world's population [28, 29]; however, the disability prevalence is increasing steadily due to a combination of factors, such as aging, health conditions, natural disasters, low income, and wars [30]. Therefore, refugees have an increased prevalence rate of disabilities globally; specifically, Syrian refugees have a higher rate of disability than other refugees. For example, $80-90 \%$ of disabilities among Syrian refugees were resulting directly from the conflict $[13,25]$ while the rate of disability among refugees in Rwanda related to the war was $0.3 \%$ [30]. Because of this high rate of disability among Syrian refugees, this study mainly targeted PSS provided to them as presented in the literature.

\section{Psychological support services}

Refugees from conflicted areas are exposed to significant psychological and social disorders, Inter-Agency Standing Committee (IASC) [31]. These disorders are results of a range of events and factors that refugees who fled from war have experienced, such as the death of a loved person, separation from family, or being subject to or witnessing violent acts $[8,9]$. PSS are a group of services that enable individuals to get over the crisis' influence by addressing their psychological and social problems [9, 32, 33]. In emergency settings, PSS should include multi-layered services to protect the well-being of individuals. These services include basic services and security, community and family supports, non-specialized supports, and specialized services [31, 34, 35]. There is a considerable number of studies that investigated the MPHSS provided for refugees [22, 36, 37]; however, it is important to explore to what extent these studies extensively investigated PSS provided to refugees with disabilities in disaster contexts $[10,38]$. It is crucial because refugees with disabilities are among people at highest risk of experiencing psychosocial problems and require MHPSS [14, 31]. Refugees with disabilities require extra care by using specialized services [38]. PSS are one of the essential services needed by refugees with disabilities according to the social model of disability and international laws that focus on the rights of persons with disabilities to have equal social opportunities with other people $[39,40]$. More importantly, refugees with disabilities are doubly vulnerable to psychological and social challenges imposed by their disabilities and asylum conditions [31, 41].

\section{Purpose}

The study aimed to systemically synthesize and thematically analyze the findings of studies related to the PSS and interventions provided to Syrian refugees with disabilities. This study targeted refugees with disabilities in conflicted areas, specifically Syrian refugees with disabilities, by addressing the following focused review question: What are the forms of PSS provided to Syrian refugees with disabilities and the critical factors related to these services?

\section{Methods}

\section{Systematic review process}

The researchers used the Centre for Reviews and Dissemination systemic review outline to collect the data 
[42]. The following databases were searched in December 2020: Google Scholar, PsychInfo, EBSCOhost, Web of Science, and Scopus. The researchers used the following search strategy:

1) (psychosocial AND disab*) OR (psycho* AND disab*) OR (social AND disab*) AND (Syrian refugee)

2) (psychosocial AND disab*) OR (psycho* AND disab*) OR (social AND disab*) AND (Syrian asylum)

3) (psychosocial AND disab*) OR (psycho* AND disab*) OR (social AND disab*) AND (Syrian displacement)

To meet the thoroughness of the search strategy, the researchers used the search strategy multiple times. In each time, they used a single primary term (Syrian refugee, asylum, or displacement) with a single supported term (psychosocial, psycho, social, and disability). These studies were reviewed to identify any psychosocial services, which refer to services that aim to address individuals' ongoing psychological and social needs, such as training programs, counseling services, support groups, rehabilitation services, or community services. On the other side, these studies were reviewed to identify that services were provided to refugees with disabilities, which refer to individuals with certain or multiple disabilities that include mobility and physical impairments, head injuries, vision disability, hearing disability, learning disabilities, autism spectrum disorder, emotional disturbance, speech or language impairment, and intellectual disability.

The inclusion criteria include articles and field reports that describe PSS provided to Syrian refugee with disabilities that officially reported by UNHCR, hosted countries in the Middle East and Europe, and internally displaced people in Syria. Moreover, the inclusion criteria included studies that were published in the English language from the beginning of the Syrian crisis in 2011 to the date of the search in December 2020.

On the other hand, studies were excluded if the study sample did not include any Syrian refugees with disabilities regardless of their percentage of participation or if they did not have precise data of the provided PSS. Figure 1 shows more details about the screening process.

\section{Analysis}

The two researchers independently screened studies' titles and abstracts and reviewed the full studies to check the inclusion and exclusion criteria. Duplicated and irrelevant items were excluded and then each identified study was double reviewed to confirm the accuracy of selection. The second researcher confirmed the studies identified by the first researcher to ensure reliability. Thereafter, the researchers thematically analyzed the identified studies by using a theoretical approach proposed by Braun and Clarke [43]. Based on this theoretical model, the researchers familiarized themselves with the identified studies by reading, rereading, and making notes for initial ideas. Then, studies sections that related to PSS provided for Syrian refugees with disabilities were coded, and themes were identified. At this point, the researchers used Klopper, Lubbe, and Rugbeer "concept matrix" to illustrate emerging themes. The concept matrix is a practical method that is used in a wide variety of disciplines and can help researchers in presenting emerged themes [44].

\section{Results}

\section{Identified studies}

The results of the systemic review showed that out of the 1072 studies included in the initial screening, nine identified studies met the inclusion criteria. These identified studies have precise data about refugee with disabilities and the PSS provided to them. Table 1 provides an overview of methodologies, participants, and findings of the identified studies included in the review.

Most of the identified studies used the mixed-method research approach to investigate the PSS provided to Syrian refugees with disabilities. Some studies focused in using field visits method to collect data, such as Crock et al. and Women's Refugee Commission [25, 27] while the majority of the study used qualitative methods, such as interviews and focus group discussions, such as Care Jordan, HelpAge International, IREX and AFPRD, Strong et al., Yamamoto and Matsuo [13, 26, 45, 46, 48, 49]. Only one study, Dababnah et al., used the experimental method by applying for a community-based intervention program with parents and teachers of Syrian refugee children with ASD [47]. This study implemented a 12week intervention program for parents and teachers of Syrian refugee children with ASD affected by trauma in Turkey. The community-based intervention sessions aimed to improve the skills of teachers and parents in behavior management, social support, promoting communication, social interaction, and adaptive behavior. Participants of the study reported gaining knowledge of new skills to support children with ASD in the community. However, surveys remain the most commonly used methodology among the reviewed studies.

The results of the review also showed that refugees with disabilities were the targeted population of most of the studies, yet few studies, such as Care Jordan included refugees with disabilities with other refugee groups and service providers $[45,46]$. Dababnah et al.'s study targeted older refugees' participants, but, overall, the participants' age was not a significant variable of studying refugees with 


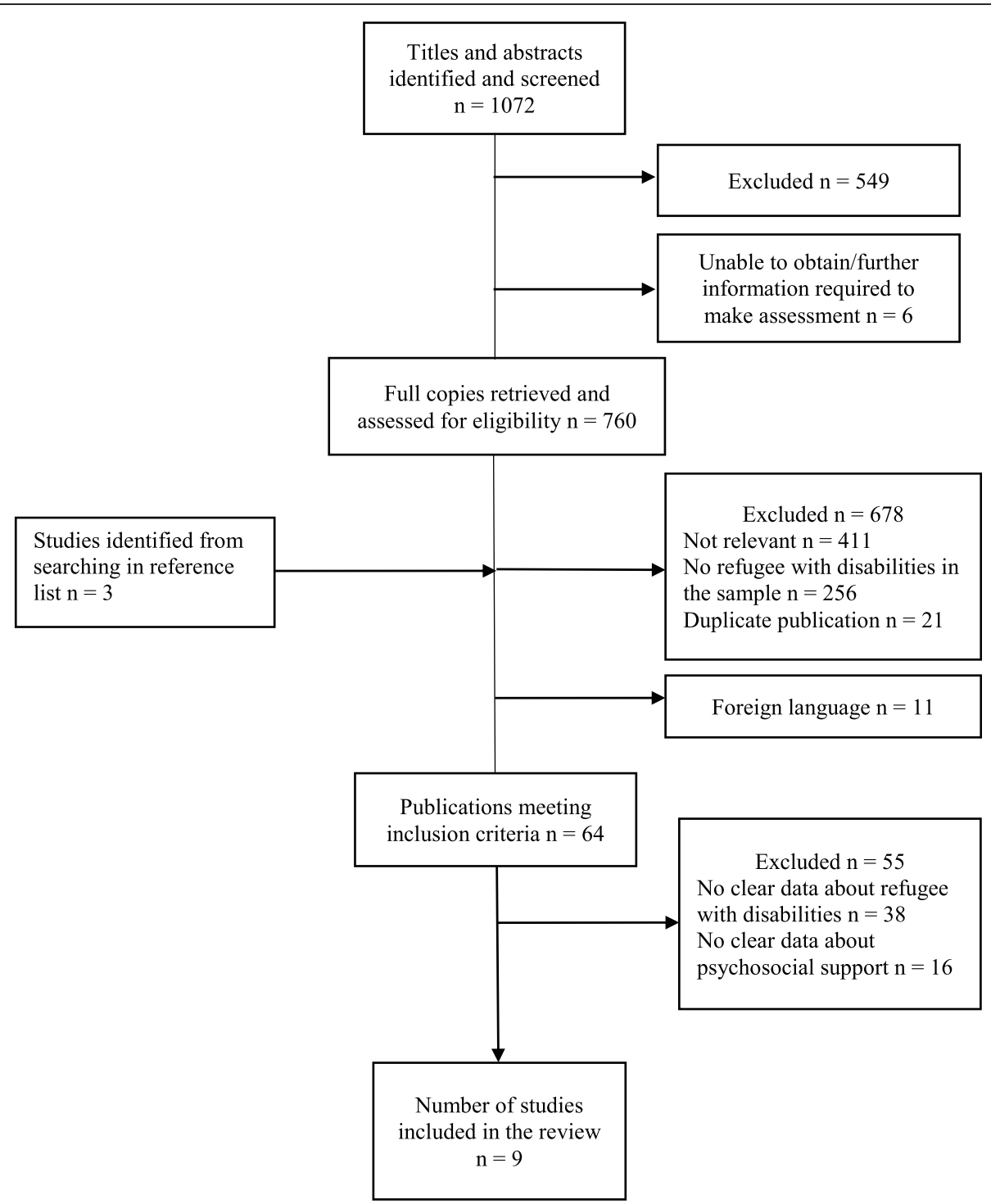

Fig. 1 Flow chart of the study screening process. Adapted from CRD's guidance for undertaking reviews in healthcare [42]

disabilities and their services [47]. It is worth mentioning that a large number of the old age participants are classified as people with disabilities because some disabilities, such as hearing loss, vision impairment, muscular disorders, and orthopedics disorders are associated with aging. Nevertheless, the numbers of participants differed from study to another, depending on the nature of the study. For example, HelpAge International survey report included thousands of participants while in experimental studies like Dababnah et al., the number of participants did not exceed 20 participants [13, 47].

Furthermore, studies' methodologies and objectives imposed the types of disabilities that were targeted. Studies that used survey methodologies studied a wide range of mental, physical, and sensory disabilities [13, 25-27]. The only study that investigated one type of disability was Dababnah et al.'s study, which examined the impact of a psychosocial intervention program on families and teachers of children with ASD [47].

\section{Themes}

The thematic analysis identified six themes that represent the PSS provided to Syrian refugees with disabilities and critical factors related to these services. The identified themes were assessment, mental health, psychological well-being, rehabilitation, social participation, and vulnerability. Table 2 shows the concept matrix of identified themes in the review.

\section{Assessment}

Assessing psychosocial needs of Syrian refugees with disabilities' theme was identified within five of the nine 
Table 1 Identified studies' data

\begin{tabular}{lll}
\hline Study & Participants & Method \\
\hline Care Jordan [45] & $\begin{array}{l}\text { 60 household (3 with refugees with } \\
\text { disabilities); 327 people surveyed (10 have } \\
\text { special needs) }\end{array}$ & $\begin{array}{l}\text { Interviews, surveys, data } \\
\text { analysis, and focus group } \\
\text { discussions }\end{array}$ \\
Care Jordan [46] & $\begin{array}{l}534 \text { household members (4\% with special } \\
\text { needs) }\end{array}$ & $\begin{array}{l}\text { Interviews, surveys, and focus } \\
\text { group discussions }\end{array}$
\end{tabular}

\section{Findings}

Refugees with disabilities reported feelings of isolation and loss of community.

Limited access to basic psychosocial support services, such as healthcare, housing, education, and food group discussions

Participants reported feelings of depression, family violence, and symptoms of psychological distress. Psychosocial support programs needed for refugees with disabilities should include psychosocial assessment and coping strategies.

Crock, Saul, McCallum and Smith-Khan [25]

Dababnah, Habayeb, Bear, and Hussein [47]

HelpAge International [13]

3202 Syrian refugees (716 refugees with impairment, 501 refugees with chronic disease, and 183 injured refugees).

9 parents and 11 teachers of refugee children with ASD.

124 refugees with disabilities, government officials, and international NGO staff in Turkey and 11 refugees with disabilities in Jordan

Field visit, interviews, discussion groups, and questionnaires

Intervention sessions and interviews

Surveys and interviews

Surveys, focus group

300 refugees with disabilities and 125 key informants discussions, and interviews

Refugees with disabilities are facing significant challenges in accessing psychosocial support programs. Psychological distress was common among Syrian refugees generally, and highest among those with a disability and older refugees.

A specialized intervention program was implemented to improve parents and teachers' skills to support refugee children with ASD. Parents and teachers' skills were improved in supporting the social behaviors of children with ASD. Participants recommend the program to others. Especially in dealing with psychological trauma.

Refugees with disabilities have frequent signs. Of psychological distress three times more than the general refugee population. Lack of services that provide psychological support to refugees with disabilities.

Limited number of refugees with disabilities' families receiving community and family support services.

Refugees with disabilities are vulnerable and less able to protect themselves from exploitation, violence, and abuse.

Refugees with mental or intellectual disabilities or those facing language barriers have obstacles to receiving needed support and services.

There is a shortage of psychological support. Services provided to refugees with disabilities.

Community and family support services for refugees with disabilities are provided in some countries.

Strong, Varady, Chahda, Doocy, and Burnham [48]
167 Syrian refugees (8\% with physical disabilities, 13\% with vision impairment, and $9 \%$ with hearing impairment)

80 humanitarian actors and 120 refugees
Surveys and interviews

Common negative emotions that affect older refugees' ability to perform day-to-day functions. Physical health and lacking support contributed to developing negative feelings among older refugees.

Limitation of access to Social Development centers and outreach services, especially to refugees with 
Table 1 Identified studies' data (Continued)

\begin{tabular}{|c|c|c|c|}
\hline Study & Participants & Method & Findings \\
\hline & & & $\begin{array}{l}\text { severe disabilities, who are most } \\
\text { vulnerable to social isolation and } \\
\text { exclusion. } \\
\text { Vulnerable refugees with disabilities } \\
\text { and their families need to be } \\
\text { included in available community } \\
\text { centers' activities in order to build } \\
\text { their capacity and resilience, as well } \\
\text { as providing positive psychosocial } \\
\text { outcomes. }\end{array}$ \\
\hline Yamamoto and Matsuo [49] & $\begin{array}{l}12 \text { Syrian refugees with disabilities and their } \\
\text { families }\end{array}$ & Questionnaires and interviews & $\begin{array}{l}\text { Refugees with disabilities and their } \\
\text { families had restrictions in accessing } \\
\text { community and family support } \\
\text { services. } \\
\text { Community and family support } \\
\text { services in Jordan include } \\
\text { rehabilitation, education, financial, } \\
\text { and social services. }\end{array}$ \\
\hline
\end{tabular}

studies. Specifically, Care Jordan, Crock et al., HelpAge International, and IREX and AFPRD have assessed psychosocial needs of refugees with disabilities as a part of a broad range assessment of refugees' needs, such as food, shelter, economic situation, and other needs $[13,25,26$, $45,46]$. These studies were conducted at the beginning of the Syrian asylum because of the importance of assessment's need then. Care Jordan $[45,46]$ conducted surveys to assess Syrian refugees' needs and gaps in services in Jordan. These reports indicated isolation and loss of community feelings among Syrian refugees, who would benefit from psychosocial activities, such as communication skills, counseling, and stress management $[45,46]$.

On the other hand, HelpAge International, IREX and AFPRD, and Crock et al. specifically targeted Syrian refugees with disabilities in their reports [13, 25, 26]. HelpAge International used a scale to assess psychosocial needs among refugees. The results showed that Syrian refugees with disabilities are twice likely to report signs of psychological distress compared with other refugees [13]. IREX and AFPRD reported a high level of psychological distress among Syrian refugees with disabilities in Turkey and Jordan. This report claimed that many refugees with disabilities were isolated from family, caregivers, and society, which led them to developed psychological distress, and they needed PSS [26]. Crock et al. from the University of Sydney conducted a report about Syrian refugees with disabilities in Jordan and Turkey [25].

Regarding psychosocial assessment, they reported that psychological distress level was significantly high among refugees with disabilities and older people. It is worth mentioning that previous studies that focused on the psychosocial assessment of refugees with disabilities were field reports conducted by non-governmental organizations (NGOs) and research centers. This lack of programs and research indicated that assessing the psychosocial needs of refugees with disabilities and

Table 2 Concept matrix of identified themes

\begin{tabular}{|c|c|c|c|c|c|c|}
\hline \multirow[t]{2}{*}{ Study } & \multicolumn{6}{|l|}{ Theme } \\
\hline & Assessment & Mental health & $\begin{array}{l}\text { Psychological } \\
\text { well-being }\end{array}$ & Rehabilitation & Social participation & Vulnerability \\
\hline Care Jordan [45] & $\checkmark$ & & $\checkmark$ & & & $\checkmark$ \\
\hline Care Jordan [46] & $\checkmark$ & & & & & $\checkmark$ \\
\hline Crock, Saul, McCallum, and Smith-Khan [25] & $\checkmark$ & $\checkmark$ & $\checkmark$ & $\checkmark$ & & $\checkmark$ \\
\hline Dababnah, Habayeb, Bear, and Hussein [47] & & $\checkmark$ & $\checkmark$ & $\checkmark$ & $\checkmark$ & $\checkmark$ \\
\hline HelpAge International [13] & $\checkmark$ & $\checkmark$ & $\checkmark$ & $\checkmark$ & & $\checkmark$ \\
\hline IREX and AFPRD [26] & $\checkmark$ & & $\checkmark$ & $\checkmark$ & $\checkmark$ & $\checkmark$ \\
\hline $\begin{array}{l}\text { Strong, Varady, Chahda, Doocy, and } \\
\text { Burnham [48] }\end{array}$ & & & $\checkmark$ & & $\checkmark$ & $\checkmark$ \\
\hline Women's Refugee Commission [27] & & & & $\checkmark$ & $\checkmark$ & $\checkmark$ \\
\hline Yamamoto and Matsuo [49] & & & & $\checkmark$ & $\checkmark$ & $\checkmark$ \\
\hline
\end{tabular}


providing services to them was not a priority of government sectors in hosted countries.

\section{Mental health}

Mental health was associated with PSS in three of the studies: Crock et al., Dababnah et al., and HelpAge International [13, 25, 47]. Crock et al. described the PSS provided for refugees in Jordan as comprehensive services that were associated with legal aid, yet the report indicated that more services were needed for the longterm mental health issues, such as community-based coping strategies [25]. Dababnah et al. claimed that refugee parents of children with autism spectrum disorders (ASD) and other disabilities were experiencing high levels of psychosocial distress and mental health issues [47]. Dababnah et al. negatively linked the mental health issues with forced migration and asylum status, so it designed a program for those refugees that based on trauma-informed care [47]. HelpAge International reported a shortage of PSS, mental healthcare services, and family and community support services, especially for refugees with cognitive impairment [13]. The lack of services, according to the report, was a significant challenge by families in both Lebanon and Jordan, so the report also called to increase the number of refugees with disabilities who benefit from family and community support networks and mental healthcare services.

\section{Psychological well-being}

The state of psychological well-being was a strong theme that arose in six of the studies: Care Jordan, Crock et al., Dababnah et al., HelpAge International, IREX and AFPR D, and Strong et al. [13, 25, 26, 45, 47]. These studies showed that refugees with disabilities were suffered from a range of psychological symptoms that affected their well-being. Care Jordan highlighted a wide range of traumatic symptoms among refugees with disabilities, such as anxiety, stress, and depression. These signs had an impact on refugees' psychological well-being and led to a group of consequences, such as frustration, negative feelings, and violence in the home [45]. Crock et al. reported that the state of psychological well-being of refugees with disabilities' families was affected by their displacement conditions. The report indicated that these families suffered from nervousness, anxiety, and depression, which may impact their coping abilities negatively [25]. Dababnah et al. indicated that stress, depression, and lower levels of well-being are challenges that families face when raising a child with ASD in typical circumstances, and parents of children with ASD in conflict-affected communities are more vulnerable to face these challenges [47]. HelpAge International reported that refugees with disabilities are more likely to experience psychological distress. The report listed a wide range of psychosocial distress' signs, such as a change in emotion, change in behavior, change in relationships, and change in cognition [13]. IREX and AFPR $\mathrm{D}$ indicated that isolation and separation from family are the most significant challenges facing refugees with disabilities. These challenges, according to the report, led to psychological distress and difficulties in providing needed services [26]. Strong et al. mentioned that older refugees with disabilities reported negative emotions that restricted their ability to perform generally in daily life. Those older refugees experienced negative emotions, such as anxiety, depression, fears, feeling unsafe, loneliness, irritability, and anger [48].

\section{Rehabilitation}

Six of the studies discussed the necessity of rehabilitation programs for refugees with disabilities. Rehabilitation as PSS for refugees with disabilities includes medical services, physical support services, assistive devices, vocational services, and training for independent living. Crock et al. noted the availability of rehabilitation services for refugees with disabilities in Turkey and Jordan, but there are many obstacles to providing these services. One of the most critical obstacles facing the provision of PSS in host communities was the prioritization of providing essential services such as food, medicine, education, and shelter for refugees over rehabilitation services [25]. For instance, the Women's Refugee Commission reported a shortage in the longterm rehabilitation services provided for refugees with disabilities in Lebanon; however, the health providers believe that there was a "low priority for rehabilitation interventions at this point in the humanitarian response." Therefore, the report recommended increasing attention to the rehabilitation sector for refugees with disabilities in Lebanon, especially psychological support programs for women and children [27]. Dababnah et al. reported that intervention programs could enhance the psychosocial status of parents and caregivers of children refugees with ASD by decreasing stress and increasing selfconfidence [47]. Oppositely, HelpAge International reported that there was a shortage of rehabilitation services provided for refugees with disabilities in Jordan and Lebanon. The report indicated that immediate healthcare services are available in many locations, but there was a lack of long-term rehabilitation and PSS [13]. IREX and AFPRD findings showed that disability among refugees is linked with the extra cost of providing health and rehabilitation services, which not all refugees with disabilities are getting [26]. Yamamoto and Matsuo emphasized the importance of providing rehabilitation services of refugees with disabilities; however, the results of the study showed a weakness in the provision of these services to refugees with disabilities in Jordan that 
include community and family support services, secondary and higher education services, financial services, social protection, and community mobilization [49].

\section{Social participation}

Social participation of refugees with disabilities in the community was discussed in five studies. Dababnah et al. reported that teachers and parents of children with ASD suffered from social isolation; therefore, the intervention results showed an improvement of teachers and parents' competences in enhancing the social participation of their children [47]. IREX and AFPRD indicated that refugees with disabilities have many restrictions that limit their social participation in the community. These restrictions related to the camps' infrastructure or others' attitudes, which prevent refugees with disabilities of fully participating in social life. Hence, the study recommended more PSS targeting the social skills of refugees with disabilities to ensure adequate social communication and participation [26]. Strong et al. reported a critical impact of social isolation on older refugees' daily life. The lack of social participation of older refugees, especially older people with disabilities, may cause a misrepresentation of older refugees in the community, which may affect their self-worth [48]. Women's Refugee Commission reported several cases of families of refugees with disabilities who are facing extreme social isolation and exclusion. The study recommended that outreach programs and community centers should promote social activities for refugees with disabilities based on a social and rights-based model to encourage those refugees to participate in the community effectively [27]. Yamamoto and Matsuo found that Syrian refugees with disabilities and their families in Jordan facing several restrictions that limit their social participation due to physical-limitation disabilities. The study recommended professionals to provide services that support the social engagement of refugees with disabilities [49].

\section{Vulnerability}

Vulnerability is the most robust theme that emerged in all identified studies, which described that Syrian refugees with disabilities were vulnerable groups. HelpAge International described this group of people as the "Hidden Victims" of asylum and displacement situations. The report claimed that this group of people that include people with disabilities, older adults, and children is more vulnerable to psychological disorders than other refugees, and the report recommended that psychosocial needs of those people must be assessed in order to provide support services on an ongoing basis [13]. Strong et al. concluded that elderly, disabled, women, and children; Syrian refugees are a highly vulnerable population, and they require services, especially health services [48].
Yamamoto and Matsuo reported that human rights services provided to Syrian refugees with disabilities should include particular PSS, which are just as important as other essential services they may need, such as housing and food [49].

Moreover, Care Jordan reports found that the most vulnerable groups among Syrian refugees are women, people with special needs, older people, and unaccompanied. According to these reports, vulnerable refugees require to assess their psychosocial needs and provide them with services that address these needs $[45,46]$. Dababnah et al. reported that refugees with disabilities are the most vulnerable group of people in the asylum setting who need training and rehabilitation programs that enable persons with disabilities, their families, and service providers to face the psychosocial challenges resulting from disability and asylum situations [47]. According to the Women's Refugee Commission, people with disabilities are the most socially vulnerable groups in displaced communities who are excluded and facing social, environmental, and communication obstacles. The Women's Refugee Commission called host communities and international organizations to evaluate and identify the psychosocial risks related to refugees with disabilities and provide essential support for them [27]. Likewise, IREX and AFPRD report described that people with disabilities among vulnerable Syrian refugees' people. The report claimed that people with disabilities are "among the most hidden, excluded, and neglected of all displaced persons." The report also mentioned that "isolation caused by the loss of family members or caregivers leaves PWDs vulnerable to physical and sexual violence, exploitation, human trafficking, harassment, and discrimination" [26]. On the other hand, Crock et al. encouraged host communities and health service providers to identify and assess vulnerable refugees with disabilities and consider their strengths and capabilities [25].

\section{Discussion}

This review identified nine studies exploring various forms of PSS provided to Syrian refugees with disabilities. The systematic review identified a limited number of studies that investigated psychosocial support services for refugees with disabilities compared to studies that investigated these services for refugees in general. The forms of these services included mostly basic services, community support services, and a few specialized services. The review findings also revealed that most of the identified studies argued the importance of providing PSS to refugees with disabilities and their families; however, there was limited information about the effectiveness of these services and its appropriateness for refugees with disabilities. Indeed, refugees with disabilities need specialized support 
services and adaptation in the environment to suit the type of disability at different levels that include accommodation, rehabilitation services, assistive equipment, and MHPSS. Hence, the findings of this review pointed out a gap in the specialized PSS provided Syrian refugees with disabilities with taking into consideration the large number of Syrian refugees and IDPs in general and those with disabilities in particular. The specialized PSS must comply with the criteria for providing services as a human right of refugees and IDPs with disabilities in conflicted areas [31, 39, 40].

Furthermore, available data from the review indicated that refugees with disabilities are among the most vulnerable group of refugees to develop symptoms of psychological distress. HelpAge International, for example, described those people as "hidden victims" of displacement while IREX and AFPRD and Care Jordan described them as "underserved people" $[13,26,45,46]$. Thus, the lack of provided PSS to Syrian refugees with disabilities represents a potentially long-term effect on the psychological and social well-being of those individuals.

The thematic analysis findings showed a group of factors that affect the PSS provided to Syrian refugees with disabilities. The most crucial factor was the assessment of the psychosocial needs of these individuals. The assessment of the needs leads to the appropriate provision of services and helps refugees with disabilities to overcome obstacles imposed by disabilities and asylum. Other factors related to the PSS were the mental health services that enable Syrian refugees with disabilities to achieve the psychosocial well-being. The lack of mental health care services for refugees with disabilities may cause higher levels of stress and psychosocial distress and place them at significant risk of falling into extreme vulnerability. These findings are consistent with the results of Mirza and Yohani et al.'s studies that reported that refugees with disabilities are at risk of mental disorders and in need of PSS $[14,16]$. These services increase the capacity and resilience of refugees with disabilities and their parents, teachers, and care-providers. The PSS provided to refugees with disabilities, and their families are essential as the right of refugees with disabilities.

The PSS provided to refugees with disabilities have incredible effects on their psychosocial well-being; however, this review revealed variations in the quality of services provided to refugees with disabilities and their families. Identified studies emphasized the need to provide specialized PSS and community support programs that qualify refugees with disabilities and their families to live independently. The increase in PSS could prompt the social participation of Syrian refugees with disabilities and their families in the community, which decreased the risk of psychological disaster in short and long terms.

\section{Implications}

The PSS provided Syrian refugees with disabilities have severe implications on the mental health of those refugees, who already suffer from disability restrictions, and their caregivers. The lack of PSS leads to social risk and absence of social participation and inclusion of refugees with disabilities in the community. These conditions cause severe psychological problems that can be prevented by providing community and family support. The community and family support programs for refugees with disabilities and their families may include rehabilitation, social and health services, inclusion education, employment, and entrepreneurship services. Yamamoto and Matsuo and Strong et al. emphasized the role of community participation and supporting programs in enhancing the role of refugees with disabilities in communities $[48,49]$. On the other hand, the lack of community participation of refugees with disabilities negatively affects the social participation of their families, therefore, providing community and family support programs promote the social participation of refugees with disabilities and their families.

From an economic perspective, providing PSS could impact host communities positively. On the one hand, frequent psychosocial disorders contribute to spending more on health services for refugees with disabilities and their families. On the other hand, refugees with disabilities may benefit from rehabilitation, educational, and social services provided to them, which may lead to an increase in the employment rate among refugees with disabilities and on the other side decrease the spending in financial aid and welfare programs.

Consequently, providing PSS to refugees with disabilities is a legal human right stipulated in international conventions [50]; therefore, supporting the PSS to refugees with disabilities and their families is a legal and ethical duty to help them practice their right of selfdetermination as other human beings. There is still a significant need for policies that regulate the PSS sector, especially the government services, to include evidencebased evaluation and practices as well as training programs for practitioners. Policy restructuring is particularly crucial in reforming the mental public health system, and it deserves the potential costs of providing services to refugees with disabilities and their families. More significantly, governments and NGOs should collaborate in providing PSS that may contribute to the social and economic development of refugees and local communities.

\section{Limitations}

The systematic review and thematic analysis framework used in this study ensured that the results represent a deep understanding of the PSS provided to Syrian 
refugees with disabilities. However, the findings presented in this review should be construed with the consideration of some significant limitations. First, the systematic review was limited to the available published literature about PSS provided to Syrian refugees with disabilities since the start of the Syrian crisis in 2011 to the end of 2020. Second, this review focused primarily on published literature about Syrian refugees with disabilities, which were limited. Several studies that generally investigated the PSS provided to Syrian refugee population and did not have participants with disabilities were excluded from the review. As such, studies excluded from this review even if the target population of these studies were refugees with disabilities if it did not discuss the PSS. Third, this study used a qualitative thematic analysis method to review the critical factors related to PSS. The identified themes in the analysis might only cover the most common factors in the review, which could affect the findings' transferability. Finally, this review only included the published literature in the English language, which may result in the exclusion of literature published in other languages, such as Arabic.

\section{Conclusions}

PSS are one of the essential services that affect the lives of refugees with disabilities. This study systematically reviewed and thematically analyzed studies that investigated PSS provided for Syrian refugees with disabilities in terms of availability, importance, and effectiveness of these programs on the mental health and well-being of those refugees. This review revealed that there is a lack of studies that investigated this topic; despite that, identified studies claimed that the quality, effectiveness, and availability of these services differ based on the service level (basic or specialized). Still, these studies confirmed that these services are essential for refugees with disabilities. The results of the thematic analysis identified a set of factors that affect the PSS, which were assessment, mental health, psychological well-being, rehabilitation, social participation, and vulnerability. This study recommends a set of steps that may contribute to improving the PSS provided to refugees and IDPs with disabilities. The first step toward improving the current practices in the field is the professional development of practitioners and service providers in the mental health sector. The second step in reforming the PSS is conducting more scientific researches about refugees with disabilities' psychosocial and mental health services. Researches are a significant element of enhancing the PSS provided for Syrian refugees with disabilities, which will help in assessing the needs and improving the services. Specifically, more researches are needed in assessment, quality of services, policies, community services, and intervention programs. Finally, policies restructure is a critical path to elaborate on the services and practices. Legislation could regulate the services by the legalization of the service provision for refugees with disabilities and their families, and to monitor and control the quality of the provided services. These recommendations may ensure the efficacy and the quality of PSS and enhancing the quality of life of Syrian refugees with disabilities and their families.

\section{Abbreviations \\ IDPs: Internally displaced people; WHO: World Health Organization; DSM- 5: Diagnostic and statistical manual of mental disorders-version 5; \\ IDEA: Individuals with Disabilities Education Act; IASC: Inter-Agency Standing Committee; PSS: Psychological support services; MHPSS: Mental health and psychosocial support; UNHCR: United Nation Refugee Agency; ASD: Autism spectrum disorder; NGOs: Non-governmental organizations; \\ CRPD: Convention on the Rights of Persons with Disabilities}

\section{Acknowledgements}

Not applicable.

\section{Authors' contributions}

AA and HA collected and analyzed this article. AA has a major contribution in writing the manuscript. All authors read and approved the final manuscript.

\section{Funding}

None.

\section{Availability of data and materials}

Not applicable.

\section{Declarations}

Ethics approval and consent to participate Not applicable.

\section{Consent for publication}

Not applicable.

\section{Competing interests}

The authors declare that they have no competing interests.

\section{Author details}

${ }^{1}$ Counseling and Educational Psychology Department, Yarmouk University, Irbid, Jordan. ${ }^{2}$ The Higher Council for the Rights of Persons with Disabilities, Amman, Jordan.

Received: 16 August 2021 Accepted: 18 September 2021

Published online: 10 November 2021

\section{References}

1. Esses VM, Hamilton LK, Gaucher D (2017) The global refugee crisis: empirical evidence and policy implications for improving public attitudes and facilitating refugee resettlement: the global refugee crisis. Soc Issues Policy Rev 11(1):78-123. https://doi.org/10.1111/sipr.12028

2. Reynolds M (2019) The global refugee "Crisis": learning is the key to solving it. Soc Educ 83(6):308-310

3. Chemali Z, Borba CPC, Johnson K, Khair S, Fricchione GL (2018) Needs assessment with elder Syrian refugees in Lebanon: implications for services and interventions. Global Public Health 13(9):1216-1228. https://doi.org/10.1 080/17441692.2017.1373838

4. Su D, Toure D, Do K, Latt Nlam N, Ern J (2017) Refugee health needs assessment in Omaha. University of Nebraska Medical Center, Nebraska

5. Thoresen P, Fielding A, Gillieatt S, Thoresen SH (2016) Identifying the needs of refugee and asylum-seeking children in Thailand: a focus on the perspectives of children. J Refugee Stud 30(3):few028. https://doi.org/10.1 093/jrs/few028

6. Fegert JM, Diehl C, Leyendecker B, Hahlweg K, Prayon-Blum V (2018) Psychosocial problems in traumatized refugee families: overview of risks 
and some recommendations for support services. Child Adolesc Psychiatry Ment Health 12(1):5. https://doi.org/10.1186/s13034-017-0210-3

7. Reavell J, Fazil Q (2017) The epidemiology of PTSD and depression in refugee minors who have resettled in developed countries. J Ment Health 26(1):74-83. https://doi.org/10.1080/09638237.2016.1222065

8. Stewart J, Chaar DE, McCluskey K, Borgardt K (2019) Refugee student integration: a focus on settlement, education, and psychosocial support. J Contemp Issues Educ 14(1):55-70. https://doi.org/10.20355/jcie29364

9. Weissbecker I, Hanna F, El Shazly M, Gao J, Ventevogel P (2019) Integrative mental health and psychosocial support interventions for refugees in humanitarian crisis settings. In: Wenzel T, Drožđek B (eds) An Uncertain Safety: Integrative Health Care for the 21st Century Refugees. New York City: Springer International Publishing, pp 117-153. https://doi.org/10.1007/ 978-3-319-72914-5_6

10. Stough LM, Ducy EM, Holt JM (2017) Changes in the social relationships of individuals with disabilities displaced by disaster. Int J Disaster Risk Reduction 24:474-481. https://doi.org/10.1016/j.ijdrr.2017.06.020

11. Berti B (2015) The Syrian refugee crisis: regional and human security implications. Strateg Assess 17(4):41-53

12. Crock M, Smith-Khan L, McCallum RC, Saul B (2017) The legal protection of refugees with disabilities: forgotten and invisible. Cheltenham: Edward Elgar Publishing. https://doi.org/10.4337/9781786435446

13. HelpAge International (2014) Hidden victims of the Syrian crisis: disabled, injured and older refugees.

14. Mirza MP (2019) Special issue: supporting health and psychosocial wellbeing for refugees and asylum seekers. Societies 9(3):52. https://doi.org/1 $0.3390 /$ soc 9030052

15. Rohwerder B (2018) Syrian refugee women, girls, and people with disabilities in Turkey. K4D Helpdesk Report

16. Yohani S, Kirova A, Georgis R, Gokiert R, Mejia T, Chiu Y (2019) Cultural brokering with Syrian refugee families with young children: an exploration of challenges and best practices in psychosocial adaptation. J Int Migr Integration. 20(4):1181-1202. https://doi.org/10.1007/s12134-019-00651-6

17. Bhardwaj M (2012) Development of conflict in Arab Spring Libya and Syria: from revolution to civil war. Washington Univ Int Rev 1(1):76-97

18. Ostrand N (2015) The Syrian refugee crisis: a comparison of responses by Germany, Sweden, the United Kingdom, and the United States. J Migr Human Secur 3(3):255-279. https://doi.org/10.1177/233150241500300301

19. Sirin S, Rogers-Sirin $L$ (2015) The educational and mental health needs of Syrian refugee Children

20. Byman D, Speakman S (2016) The Syrian refugee crisis: bad and worse options. The Washington Quarterly 39(2):45-60. https://doi.org/10.1080/0163 660X.2016.1204352

21. Oda A, Tuck A, Agic B, Hynie M, Roche B, McKenzie K (2017) Health care needs and use of health care services among newly arrived Syrian refugees: a cross-sectional study. CMAJ Open 5(2):E354-E358. https://doi.org/10.9778/ cmajo.20160170

22. Wells R, Steel Z, Abo-Hilal M, Hassan AH, Lawsin C (2016) Psychosocial concerns reported by Syrian refugees living in Jordan: systematic review of unpublished needs assessments. Br J Psychiatry 209(2):99-106. https://doi. org/10.1192/bjp.bp.115.165084

23. Disabilities. http://www.who.int/topics/disabilities/en/. Accessed 17 May 2020

24. American Psychiatric Association (ed) (2013) Diagnostic and statistical manual of mental disorders: DSM-5, 5th edn. Am Psychiatr Assoc. https:// doi.org/10.1176/appi.books.9780890425596

25. Crock M, Saul B, McCallum R, Smith-Khan L (2015) Syrian refugees with disabilities in Jordan and Turkey. University of Sydney. https://doi.org/1 0.13140/RG.2.1.1485.1044

26. IREX, AFPRD (2016) Disability inclusion among refugees in the Middle East and North Africa: a needs assessment of Libya, Egypt, Yemen, Jordan, and Turkey.

27. Women's Refugee Commission (2013) Disability inclusion in the Syrian refugee response in Lebanon.

28. Factsheet on Persons with Disabilities. United Nations, Department of Economic and Social Affairs.

29. World Health Organization, The World Bank (2011) World report on disability. Geneva: WHO.

30. Thompson S (2017) Disability prevalence and trends [K4D Helpdesk Report]. Institute of Development Studies.

31. Inter-Agency Standing Committee (2007) IASC quidelines on mental health and psychosocial support in emergency settings. IASC.
32. International Federation of Red Cross and Red Crescent Societies (2009) Psychosocial interventions: a handbook. International Federation Reference Centre for Psychosocial Support.

33. Psychosocial Support. https://www.who.int/hiv/topics/psychosocial/support/ en/. Accessed 19 May 2020.

34. Schafer A, Ndogoni L (2014) Mental health and psychosocial support in emergencies: exploring the potential of faith to enhance response and recovery. J Psychol Christianity 33(2):184-193

35. Wessells MG (2009) Do no harm: toward contextually appropriate psychosocial support in international emergencies. Am Psychol 64(8):842854. https://doi.org/10.1037/0003-066X.64.8.842

36. Cantekin D (2019) Syrian refugees living on the edge: policy and practice implications for mental health and psychosocial wellbeing. International Migration 57(2):200-220. https://doi.org/10.1111/imig.12508

37. Hendrickx M, Woodward A, Fuhr DC, Sondorp E, Roberts B (2019) The burden of mental disorders and access to mental health and psychosocial support services in Syria and among Syrian refugees in neighboring countries: a systematic review. J Public Health. 42(3):e299-e310. https://doi. org/10.1093/pubmed/fdz097

38. Hassan G, Ventevogel P, Jefee-Bahloul H, Barkil-Oteo A, Kirmayer LJ (2016) Mental health and psychosocial wellbeing of Syrians affected by armed conflict. Epidemiol Psychiatr Sci 25(2):129-141. https://doi.org/10.1017/S204 5796016000044

39. Peek L, Stough LM (2010) Children with disabilities in the context of disaster: a social vulnerability perspective: children with disabilities in disaster. Child Dev 81(4):1260-1270. https://doi.org/10.1111/j.1467-8624.201 0.01466.x

40. Runswick-Cole K, Goodley D (2013) Resilience: a disability studies and community psychology approach: disability and resilience. Soc Pers Psychol Compass 7(2):67-78. https://doi.org/10.1111/spc3.12012

41. Sherwood NR (2019) Modeling resilience in resettled Syrian refugees with disabilities. Master Thesis, The University of Alabama

42. Centre for Reviews and Dissemination (ed) (2009) CRD's guidance for undertaking reviews in healthcare, 3rd edn. Layerthorpe: York Publ Services.

43. Braun V, Clarke V (2006) Using thematic analysis in psychology. Q Res Psychol 3(2):77-101. https://doi.org/10.1191/1478088706qp063oa

44. Klopper R, Lubbe S, Rugbeer H (2007) The matrix method of literature review. Alternation 14(1):262-276

45. Jordan C (2012) Baseline assessment of community identified vulnerabilities among Syrian refugees living in Amman

46. Jordan C (2013) Syrian refugees in urban Jordan: baseline assessment of community-identified vulnerabilities among Syrian refugees living in Irbid, Madaba. ALNAP, Mufraq and Zarqa

47. Dababnah S, Habayeb S, Bear BJ, Hussein D (2019) Feasibility of a traumainformed parent-teacher cooperative training program for Syrian refugee children with autism. Autism 23(5):1300-1310. https://doi.org/10.1177/13623 61318805368

48. Strong J, Varady C, Chahda N, Doocy S, Burnham G (2015) Health status and health needs of older refugees from Syria in Lebanon. Confl Health 9(1):12. https://doi.org/10.1186/s13031-014-0029-y

49. Yamamoto S, Matsuo $H$ (2017) Current situation and challenges regarding the social participation of Syrian refugees with disabilities in urban areas of Jordan. Asian J Occup Ther 13(1):87-93. https://doi.org/10.11596/asiajot.13.87

50. Convention on the Rights of Persons with Disabilities (CRPD), Human Rights (2007) testimony of United Nations.

\section{Publisher's Note}

Springer Nature remains neutral with regard to jurisdictional claims in published maps and institutional affiliations. 